Jenny M. Drnevich $\cdot$ Emily F. Hayes

Ronald L. Rutowski

\title{
Sperm precedence, mating interval, and a novel mechanism of paternity bias in a beetle (Tenebrio molitor L.)
}

Published online: 18 January 2001

(C) Springer-Verlag 2001

Behav Ecol Sociobiol (2000) 48:447-451

The above article was communicated by D.T. Gwynne.

J.M. Drnevich ( $)$ - E.F. Hayes · R.L. Rutowski

Department of Biology, Arizona State University,

Tempe, AZ 85287-1501, USA

e-mail: drnevich@asu.edu

Tel.: +1-480-9654365, Fax: +1-480-9652519 